\title{
Quantitative UV-absorption imaging of liquid fuel films and their evaporation
}

\author{
Kamal Shway ${ }^{\star 1,2}$, Michele Bardi ${ }^{1}$, Gilles Bruneaux ${ }^{1}$, Sebastian A. Kaiser ${ }^{2}$ \\ ${ }^{1}$ IFP Energies Nouvelles, Institut Carnot IFPEN Transports Energie, France \\ ${ }^{2}$ Institute for Combustion and Gas Dynamics - Reactive Fluids, \\ University of Duisburg-Essen, Germany \\ *Corresponding author email: kamal.shway-shway@ifpen.fr
}

\begin{abstract}
Spray impingement and the resulting liquid fuel films are main causes of soot emissions in gasoline direct-injection (GDI) engines. This work presents an experimental investigation of liquid fuel-film formation and evaporation with UV-absorption imaging at a condition representative for engines. One of the 8-hole "Spray G" injectors from the Engine Combustion Network (ECN) was used in a constant-volume vessel, with a transparent plate mounted perpendicular to the injector axis at $30 \mathrm{~mm}$ from the nozzle. A fuel surrogate consisting of $30 \%$ toluene and $70 \%$ iso-octane was injected at 200 bar. The gas and wall temperature were $100^{\circ} \mathrm{C}$, and the gas pressure 1 bar.

Spatio-temporally resolved measurements of the film thickness were obtained by high-speed imaging of the UV absorption of toluene. For this purpose, the plate that the sprays impinged on was illuminated with an array of UV LEDs at $265 \mathrm{~nm}$, collecting the transmitted light with an intensified CMOS camera. Since vapour and liquid cannot be distinguished spectrally, morphological post-processing was developed to separate them based on spatio-temporal features in their appearance in the image sequences. The images then provide quantitative information on the evolution of the films thickness, mass, and surface area.
\end{abstract}

\section{Keywords}

Liquid fuel film, UV absorption, film thickness, imaging, Engine Combustion Network

\section{Introduction}

Direct injection (DI) of fuel in gasoline engines increases the efficiency, reducing carbon dioxide emissions and fuel consumption. However, it may cause an increase in carbon particulate emissions if the spray impinges on piston or liner and forms liquid films. These films evaporate slowly, and after ignition, they can interact with the premixed flame, producing soot. Euro 6 standards introduced new regulations on the particulate number (PN) emissions for vehicles, necessitating a closer look at all soot formation mechanisms in gasoline direct injection (GDI) engines.

Spray impingement and piston wetting has been studied in a optically accessible engines using laser induced fluorescence (LIF). In a DISI engine, Drake et al. [1] found soot formation from fuel-rich zones that originated after ignition from liquid fuel films. After several fired cycles, the presence of liquid fuel films on the piston caused black carbon deposits [2]. Previous studies in our own research group used LIF to image GDI fuel film formation on a quartz plate placed inside a constant volume cell. Bardi et al. [3] qualitatively assessed the fuel film formation in an optical engine at cold conditions $\left(T_{\text {wall }}=30^{\circ} \mathrm{C}\right)$, and detected liquid fuel on the valve seat, the injector nozzle, the top of the piston, and the cylinder walls. Fuel film formation was studied in a constant-flow facility [4]. The persistence of the fuel film after 
combustion caused soot formation close to the wall. Fuel vapour mainly emerges from deposited fuel films. The hot gases mix with the evaporated liquid fuel films and that leads to soot formation. The evaporation of liquid films was also studied in a constant volume cell at different plate temperatures [5]. Fuel-rich regions of vapour close to the plate were produced at temperatures less than $200^{\circ} \mathrm{C}$ and caused soot formation.

Several diagnostics have been employed to detect and quantify liquid-film thickness in engine relevant cases. As seen in the discussion above, LIF is frequently used. Typically, a fluorescing marker ("tracer") is added to a non-fluorescent base fuel. For thin fuel films, weak excitation, and low tracer concentration, the intensity of the fluorescence signal from the film is linearly dependent on the film thickness. [4,6-8]. LIF has high sensitivity, but quantification can be challenging due to the complex photophysics of fluorescence. Fuel film thicknesses were measured by Geiler et al. [6] in a DISI engine using LIF. They found that the LIF signal of toluene and 3-pentanone decreased with increasing temperature, but much more so for toluene. The linearity between the concentration and the fuel film thickness was also studied for different tracer concentrations. The quenching of the fluorescence by oxygen in the liquid fuel also can complicate quantitative measurements with LIF [6].

Refractive index matching (RIM) [1] allows imaging the liquid film thickness deposited on an illuminated, roughened material surface. The variation in the scattered light between dry and wet surfaces is related to the fuel film thickness [1,9-12]. RIM proper is applicable only to transparent surfaces, but variations for opaque, reflective surfaces, e.g., rough metal, have been developed [13]. The main strengths of RIM are that it works for any fuel and is not affected by ambient conditions. However, the surface needs to be dry before the measurement, and the presence of any residue from a previous experiment decreases the measurement accuracy. For each surface roughness, films thicknesses can be measured only in a limited range.

Another candidate technique for liquid thickness measurement is ultraviolet (UV) absorption. This technique is documented much less in the literature. It was used in a rapid compression machine (RCM) [14] to measure the film thickness on the piston after gasoline DI. Compared to LIF, UV absorption is less sensitive to temperature, and it is not sensitive to the presence of oxygen. However, in both techniques, fuel vapour may interfere with the liquid-phase measurement.

This work studies liquid film formation and evaporation in a constant volume cell at thermodynamic conditions relevant to GDI engines. UV absorption was used to perform spatio-temporally resolved measurements of the evaporating liquid film with $\mathrm{kHz}$ frame rates. We first describe experiment and then summarize the photometric quantification of the images. Morphological post-processing was developed to distinguish liquid fuel films from vapour based on their spatio-temporal characteristics. The contribution of vapour absorbance over liquid film regions was estimated. For one fuel spray, the evolution of the liquid film thickness, mass, and surface area is calculated.

\section{Methods and Materials Experiment}

The experiments were carried out in a high-pressure high-temperature constant volume cell at IFPEN [15,16]. The cell's initial conditions are set to be representative of those encountered in the combustion chamber of a GDI engine at the time of the injection. The initial temperature of the bath gas nitrogen is controlled by the cell wall heating. The cell has 
a volume of $1.3 \mathrm{~L}$, and four optical windows of $80 \mathrm{~mm}$ diameter. The fuels films that are investigated here are formed by the spray plumes from a high-pressure multi-hole gasoline injector impacting onto a transparent plate positioned $30 \mathrm{~mm}$ below it. The experimental layout and the experimental conditions are shown in Figure 1.

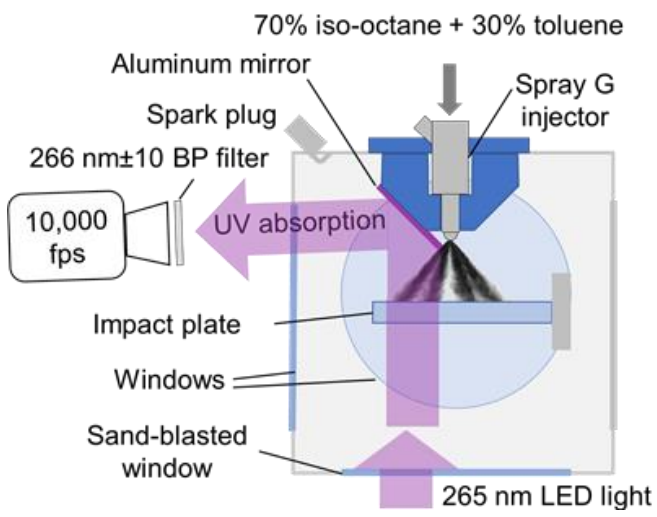

\begin{tabular}{|l|l|}
\hline Injector & $\begin{array}{l}\text { Spray G AV67 - 022 [17] } \\
8 \text {-hole injector }\end{array}$ \\
\hline Fuel surrogate & $\begin{array}{l}30 \% \text { toluene }+ \\
70 \% \text { iso-octane }\end{array}$ \\
\hline $\mathrm{p}_{\text {cell }}$ & $1 \mathrm{bar}$ \\
\hline $\mathrm{T}_{\text {wall }}$ & $100^{\circ} \mathrm{C}$ \\
\hline $\mathrm{p}_{\text {injection }}$ & $200 \mathrm{bar}$ \\
\hline $\mathrm{T}_{\text {fuel }}$ & $90^{\circ} \mathrm{C}$ \\
\hline $\mathrm{t}_{\text {injection }}$ & $0.78 \mathrm{~ms}$ \\
\hline
\end{tabular}

Figure 1. (left) Schematic of the constant volume vessel and the imaging optics, and (right) a table summarizing the experimental conditions

\section{Optics}

The main spectral features of LED emission and toluene UV absorption, measured with a fibre-pickup spectrometer (Ocean Optics USB 2000+) and a UV-visible spectrophotometer (Varian Cary 400 Scan), respectively, are shown in Figure 2. Toluene strongly absorbs light at wavelengths below about $270 \mathrm{~nm}$. A schematic of the UV absorption optical setup is shown in Figure 1. A light emitting diode (LED) array emits UV light at $268 \mathrm{~nm}$ center wavelength (CWL) with a full width at half maximum (FWHM) of $15 \mathrm{~nm}$. The array has 72 LEDs, a total optical power of $2 \mathrm{~W}$, and an emission angle of $25^{\circ}$. The incident light was diffused by a sandblasted sapphire window installed in the bottom of the cell. After passing through the quartz plate and the liquid fuel films, the transmitted light is then directed to the detection system by an aluminium mirror. A band pass (CWL $266 \mathrm{~nm}$, FWHM $20 \mathrm{~nm}$ ) filter is mounted in front of the $\mathrm{f} / 2.8$ camera lens. The camera was tilted slightly downward to optimize the camera's field of view with the given window geometry. The frame rate of the intensified CMOS camera was 10,000 frames/second with an intensifier gate time (= effective exposure time) of $98 \mu \mathrm{s}$.

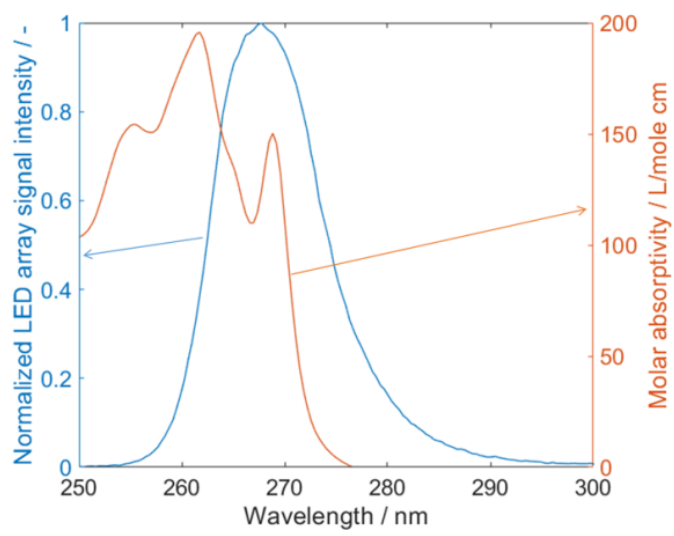

Figure 2. Spectra of the LED emission (left axis) and of toluene UV absorption (right axis)

\section{Photometric image quantification}

Based on Beer-Lambert's law [18,19], the absorbance A is determined via equation (1): 


$$
A=-\log _{10}\left(\frac{I}{I_{\text {ref }}}\right)=-\log _{10}\left(\frac{I_{t}-I_{\text {dark }}}{I_{\text {ref }}-I_{\text {dark }}}\right)=\mathrm{d} \text { c } \varepsilon
$$

where $I_{t}$ is the image at time $t, I_{\text {ref }}$ is a reference image, and $I_{\text {dark }}$ is a dark image. $d$ is the thickness of the film, and $\mathrm{c}$ the concentration of the absorbing species, and $\varepsilon$ its molar absorptivity. In reality, $\varepsilon$ and $c$ might vary with the thermodynamic conditions and due to preferential evaporation, respectively [20]. In this work, they are considered constant.

An in-situ calibration was performed by placing a cuvette with $10 \mathrm{~mm}$ inside path length $\mathrm{d}$ in the high-pressure cell. The fuel, consisting of $30 \%$ toluene in $70 \%$ iso-octane, was diluted 1:1000 in a non-absorbing solvent. This corresponds to $10 \mu \mathrm{m}$ of pure fuel thickness. The measured mean in-situ absorbance at $50^{\circ} \mathrm{C}$ was $A=0.27$ with a standard deviation of \pm 0.002 among three repetitions. Fuel film thickness are then calculated from the absorbance via $d=37 \mu m^{-1} A$.

\section{Results}

\section{Fuel film images}

Figure 3 (first and second rows) shows selected images from a time sequence of consecutive single shot images. The image at $0.5 \mathrm{~ms}$ after (hydraulic) start of injection (aSOI) shows the fuel spray impinging on the quartz plate during injection. At $1 \mathrm{~ms}$, the injection has stopped, and at $1.5 \mathrm{~ms}$, the fuel film is completely deposited on the plate. Between 1 and $2 \mathrm{~ms}$, the momentum of the spray causes movement of the fuel film on the plate. The airflow, created above the plate, induces shear forces pushing the liquid fuel film outward. After $4 \mathrm{~ms}$, a vapour cloud, created from the evaporated fuel spray along the injector axis, is brought by the spray momentum from the top center of the image down over the deposited fuel films before it disappears after $10 \mathrm{~ms}$. Between 4 and $10 \mathrm{~ms}$ this vapour is present in all images, and it causes an increase in the absorbance.

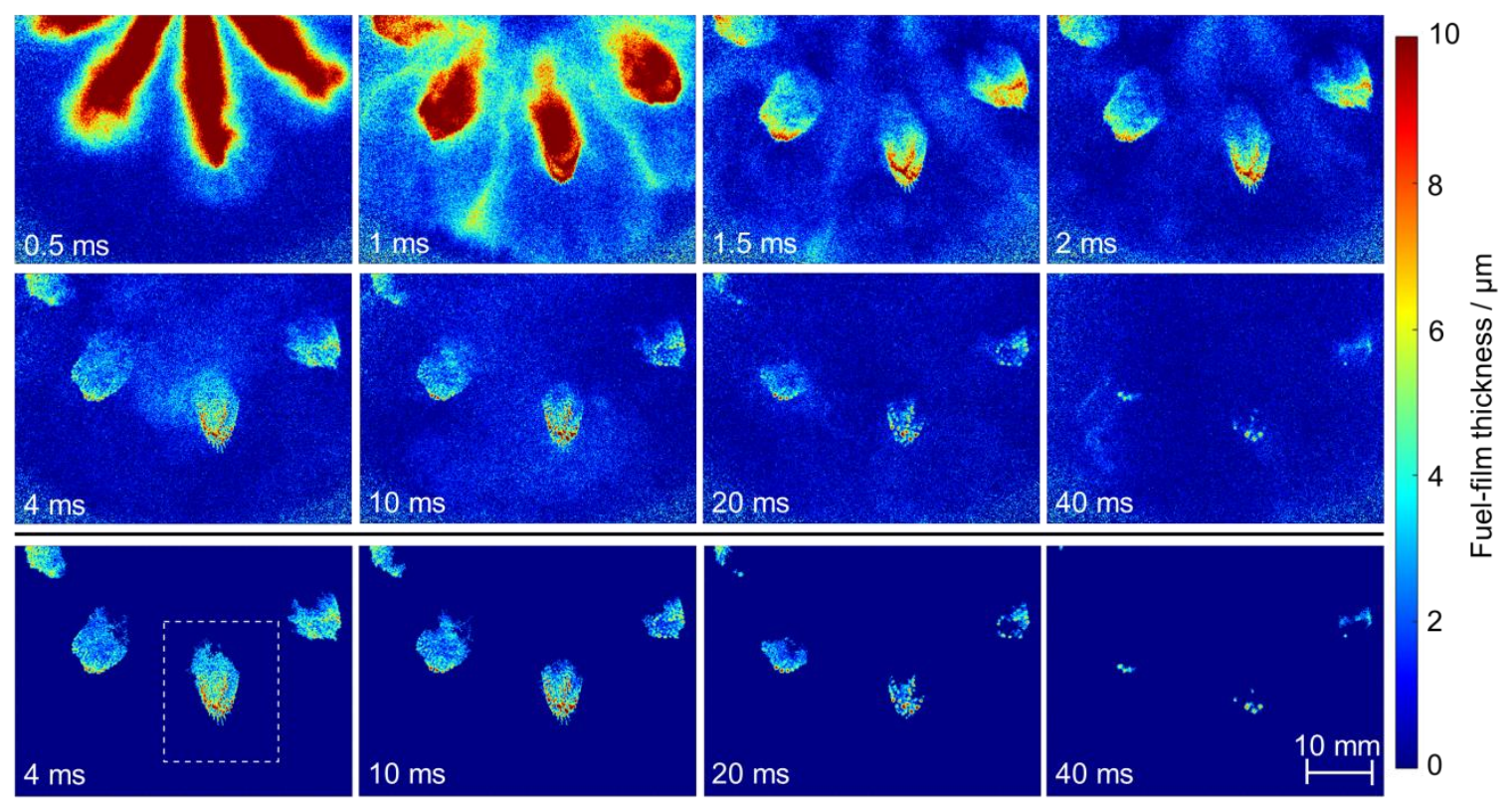

Figure 3. Time sequence of the UV-absorption derived fuel film thickness before (first and second rows) and after (third row) masking out regions with significant vapour contribution in post-processing. Time are given with respect to hydraulic start of injection. The white rectangle marks the region examined more closely in Figure 6 and Figure 7.

The time sequence shows that evaporation is more prominent at the upstream, inward edges of the fuel films (i.e., those oriented towards the injector) where thicknesses are 
smaller than that at the downstream, outward edges. After $10 \mathrm{~ms}$, the film accumulates into small droplets, with the thin fuel between the droplets disappearing before the thicker droplets themselves.

\section{Post processing}

Vapour from the evaporating liquid adds to the absorption by the liquid fuel films and is spectrally indistinguishable. To improve the accuracy of the film thickness measurement, a morphological post-processing algorithm, schematically shown in Figure 4, was developed. The algorithm segments the image into three levels: a background that represents the image noise, a mid-ground that represents the vapour, and a foreground that represents the liquid fuel film. Based on that segmentation, the absorbance of vapour in liquid-film regions was then approximated by interpolation, as indicated in Figure 5, and subtracted from the measured absorbance. The morphological processing proceeds through the calculation of three binary masks, as outlined below and in Figure 4. For the purpose of this study, the images were subsampled at $2 \mathrm{kHz}$ to reduce computational time. If not mentioned otherwise, an average dark image was subtracted from all images before any of the processing described here.

Spatial mask: A reference image $I_{\text {ref }}$ is calculated as the mean of several images acquired before injection. The shot noise was estimated from the ratio of $I_{1}$ to $I_{\text {ref, }}$ where $I_{1}$ is a single image before injection. The spatial mean $\overline{\mathrm{I}_{1} / \mathrm{I}_{\text {ref }}}$, and the spatial standard deviation $\operatorname{std}\left(\mathrm{I}_{1} / \mathrm{I}_{\mathrm{ref}}\right)$ were calculated. A threshold of $\overline{\mathrm{I}_{1} / \mathrm{I}_{\text {ref }}}-2 \cdot \operatorname{std}\left(\mathrm{I}_{1} / \mathrm{I}_{\text {ref }}\right)$ represents the shot noise absorbance level (background) in the images and separates it from the absorbance levels of the fuel vapour and liquid film (mid-ground and foreground, respectively). The result is a time series of binary masks SM.

First spatio-temporal mask: Starting from $1.5 \mathrm{~ms}$ aSOI, the approximate time when the fuel film is completely deposited on the plate, an inter-frame subtraction with a time base of $1.5 \mathrm{~ms}$ is applied to the time series of spatial masks derived above. The physical idea behind this is that the liquid fuel film moves very little, but the vapour is transported significantly by convection in an interval of $1.5 \mathrm{~ms}$. Therefore, in the result, all zero pixels are taken to correspond to the liquid fuel and are assigned the value 1, while non-zero pixels correspond to vapour and are set to 0 . This "temporal mask" TM1 is multiplied with the "spatial mask" SM. We designate the result as "spatio-temporal mask" STM1 to reflect the nature of the operation that it resulted from, but in fact it is another sequence of binary spatial masks.

Second spatio-temporal mask: Each STM1 in the time sequence is subtracted from STM1 at $2.5 \mathrm{~ms}$ aSOI, considered as a reference mask. This is based on the observation that the surface of the fuel film decreases during evaporation. In the resulting temporal mask TM2, again 0 corresponds to liquid and is set to 1 , while non-zero indicates vapour and is set to 0 . A second series STM2 of "spatio-temporal" mask representing the liquid fuel film (the foreground) is obtained by multiplication of the STM1 with TM2

The ratio images $\mathrm{I} / \mathrm{I}_{\text {ref }}$ are then multiplied by the corresponding mask STM2 and converted into absorbance, and then film thickness. A time sequence of the masked fuel film thicknesses is shown in the third row of Figure 3. The morphological post-processing defines the regions of predominately liquid fuel films but does not account for the contribution of vapour absorbance in these regions. An algorithm to correct for that vaporassociated absorbance was developed and applied to the region within the dashed white lines in the left bottom image of Figure 3 that contains one of the fuel films. 


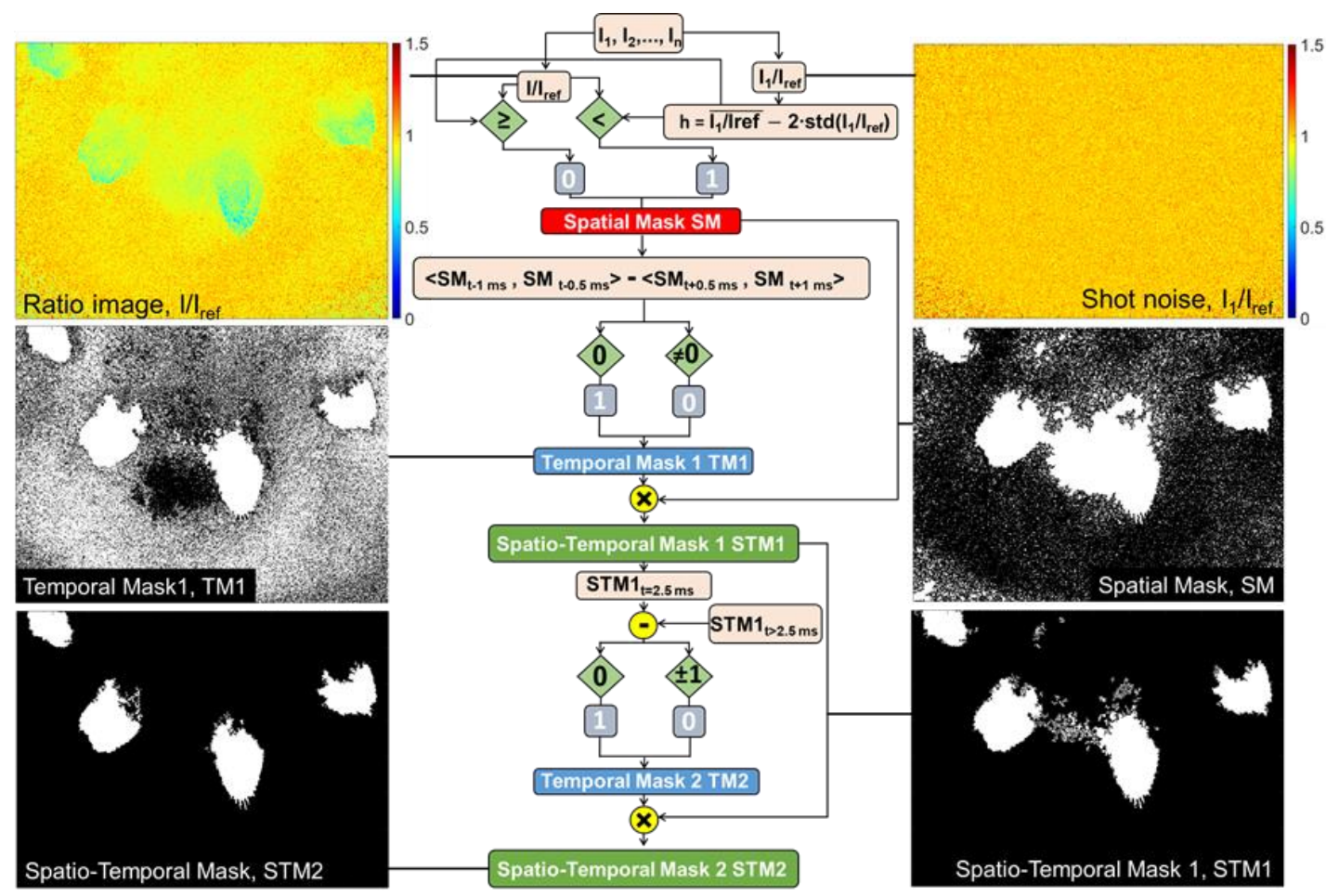

Figure 4. Flowchart of the morphological image processing for separating background, vapour, and liquid films.

First, the spatio-temporal mask STM2 is dilated horizontally and vertically by 20 pixels. This dilated mask is then subtracted from the spatio-temporal mask STM2, yielding a 20-pixel thick edge mask around the liquid-film region. This edge mask is multiplied with the unmasked images of absorbance (Figure 5a) to yield an image of absorbance surrounding the liquid film, as shown in Figure 5b. The contribution of vapour absorbance inside of this edge is then approximated by bilinear interpolation between the mean absorbance values in the edge. Figure $5 \mathrm{c}$ shows the vapour-dominated region filled in with this interpolation, but in fact to obtain "vapour-corrected" images (Figure 5e), we simply subtract the interpolated image from the already masked images (Figure $5 \mathrm{~d}$ ) that were the output of the morphological processing described above.
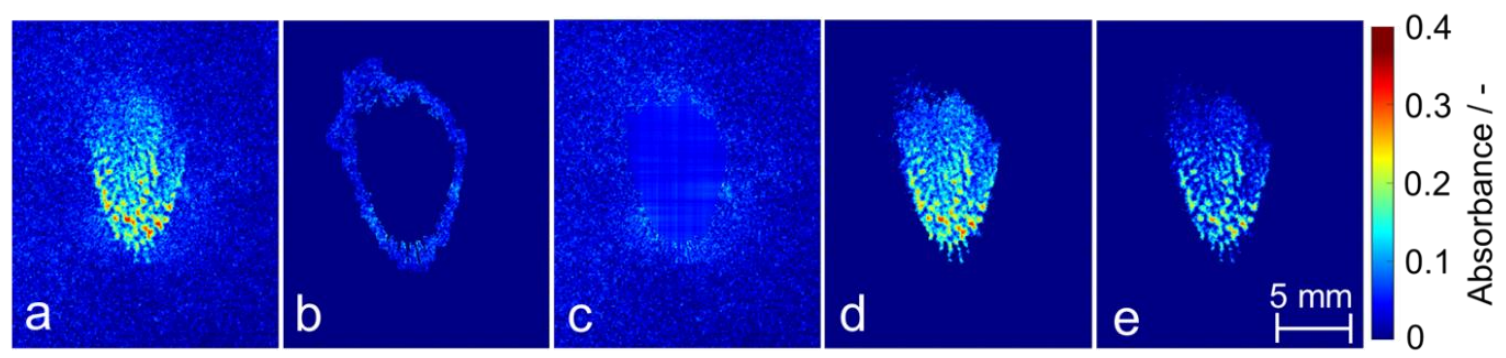

Figure 5. Approximation of the vapour contribution in the absorbance of the liquid fuel film (here at $7 \mathrm{~ms}$ aSOI). a) Absorbance as calculated via Eq.1, b) dilated edge of foreground mask, c) interpolation-based estimate of the vapour absorbance, d) foreground-masked absorbance, and e) vapour-corrected fuel-film absorbance.

The top row of Figure 6 shows selected images from a time sequence of the fuel film thickness after vapour correction. The fuel mass decreases by $68 \%$ between 4 and $20 \mathrm{~ms}$ aSOI. Only $7 \%$ of the initial fuel mass remains on the plate at $40 \mathrm{~ms}$ aSOI. The bottom row of Figure 6 gives an impression of the reproducibility of the injection-induced fuel film, 
showing the film at a fixed time, $7 \mathrm{~ms}$ aSOI, for five other repetitions. While the overall structure of the film is always the same, small-scale differences between different injections are visible. The fuel mass at this time varied between 0.069 and $0.089 \mathrm{mg}$ in the 6 repetitions represented in Figure 6.
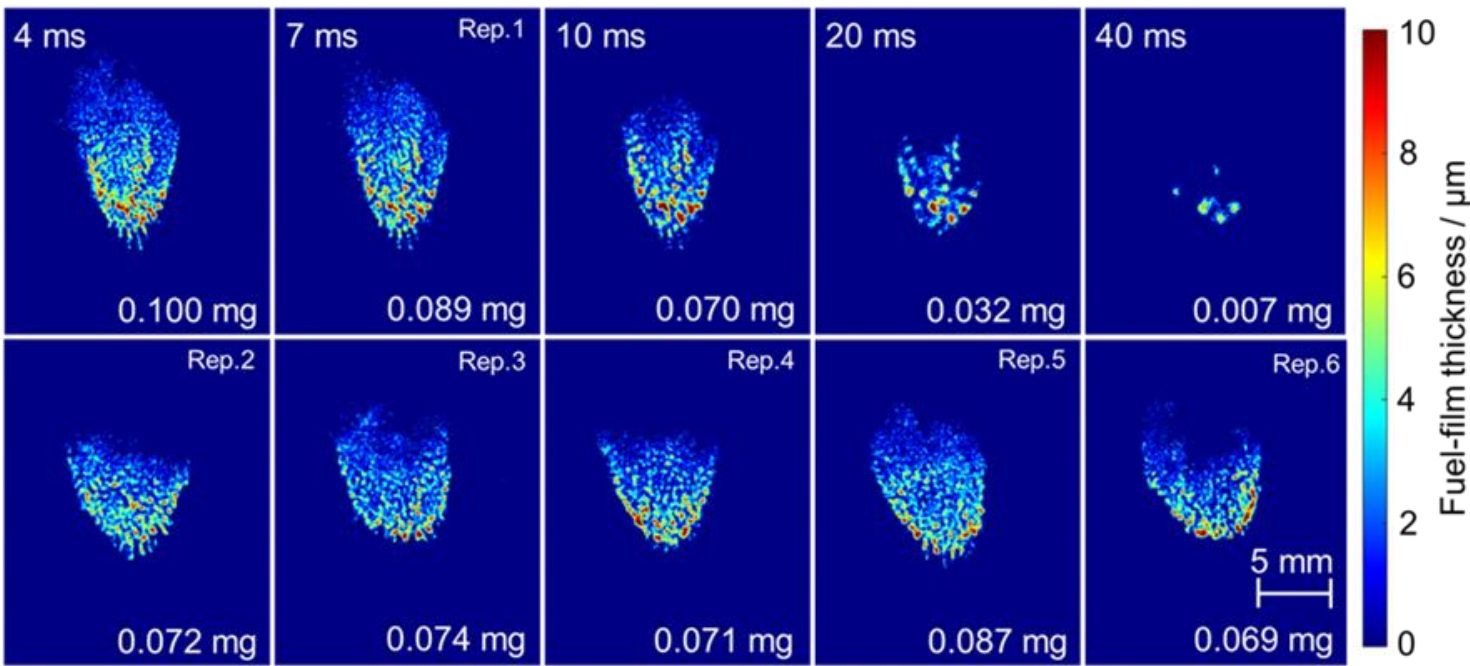

Figure 6. (top row) Selected images from a sequence of the vapour-corrected fuel film thickness between 4 and $40 \mathrm{~ms}$. (Bottom row) images from another 5 repetitions of the experiment, each at $\mathrm{t}=7 \mathrm{~ms}$ aSOI. The total mass of the film is given in the bottom-right corner of each image.

For this fuel film, Figure 7 a plots the average fuel mass in eight injection repetitions. The overall fuel mass injected per spray plume is $1.25 \mathrm{mg}$. The average fuel mass deposited on the plate is $0.11 \mathrm{mg}$ (at $2 \mathrm{~ms}$ aSOI), which is $8.8 \%$ of the total injected mass. From $2 \mathrm{~ms}$ to $30 \mathrm{~ms}$, the fuel mass decreases by $89 \%$. The maximum vapor mass above the film (i.e., the difference between corrected and uncorrected liquid film mass) peaks with $0.052 \mathrm{mg}$, or $39 \%$ of the uncorrected liquid-film mass, at $7 \mathrm{~ms}$. The contribution of vapour in the absorbance remains significant throughout until the liquid film cannot be detected anymore at $t=70 \mathrm{~ms}$. Figure $7 \mathrm{~b}$ shows that the vapor correction reduces the surface area of the fuel film much less than its mass - less than $10 \%$ between $t=2 \mathrm{~ms}$ and $25 \mathrm{~ms}$. Nevertheless, the decrease in the liquid surface by correction of vapour absorbance shows that some regions of the as-imaged film only correspond to the absorbance of vapour.
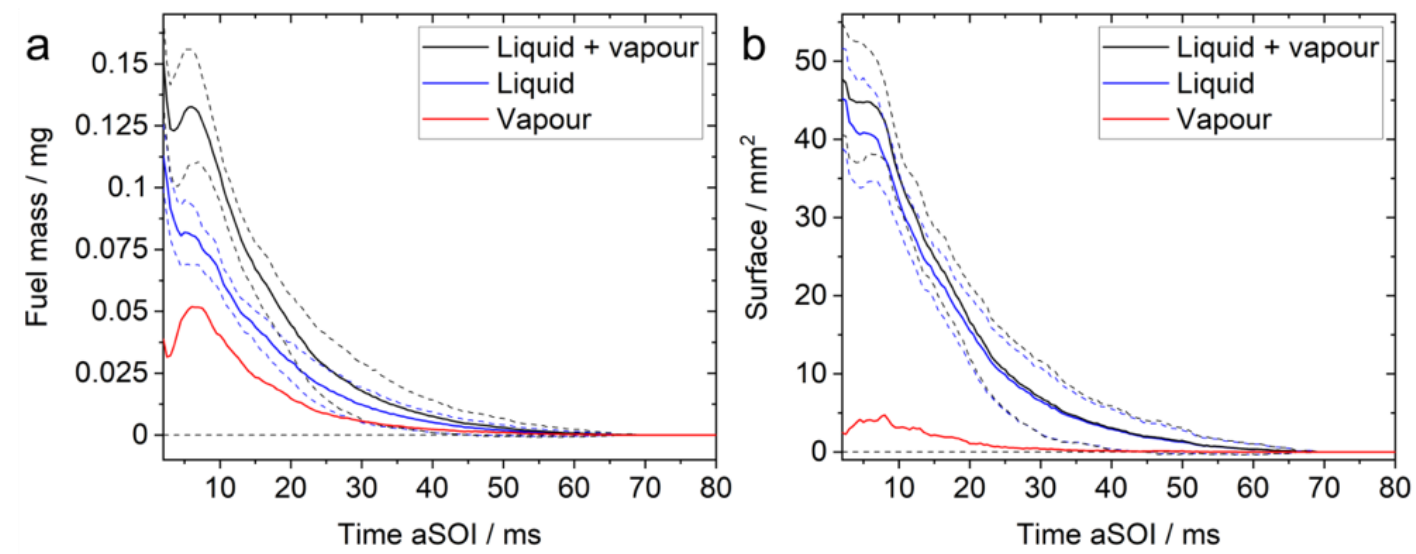

Figure 7. Evolution of a) the average fuel film mass, b) the average fuel film surface, each before and after vapour correction (black and blue trace), and the vapour above the film only, i.e, the difference between blue and black traces (red trace). The dashed lines indicate one standard deviation 


\section{Conclusions}

Spatio-temporally resolved measurements of the liquid fuel-film thickness on a transparent plate after spray impingement were obtained by UV absorption imaging. The contribution of vapour in the absorbance was significant, and an algorithm was developed to correct for its contribution. The global parameters fuel mass and film surface were then obtained. In future work, the uncertainties of the technique need to be assessed in more detail.

\section{References}

[1] Drake, M.C., Fansler, T.D., Solomon, A.S., Szekely G. A. Jr, 2003, SAE Technical Paper, 2003-010547.

[2] Stevens, E. and Steeper Richard, 2001, SAE Technical Paper, 2001-01-1203.

[3] Bardi, M., Pilla, G., Gautrot, X., 2018, International Journal of Engine Research, 20(1), pp. 128140.

[4] Jüngst, N. and Kaiser, S., 2019, SAE Technical Paper, 2019-01-0293.

[5] Roque, A., Foucher, F., Imoehl, W., Helie, J., 2019, SAE Technical Paper, 2019-01-0251.

[6] Geiler, J.N., Grzeszik, R., Quaing, S., Manz, A., Kaiser, S.A., 2017, International Journal of Engine Research, 19(1), pp. 134-147.

[7] Alonso, M., Kay, P.J., Bowen, P.J., Gilchrist, R., Sapsford, S.M., 2012, Atomization and Sprays, 22(1), pp. 79-95.

[8] Alonso, M., Kay, P.J., Bowen, P.J., Gilchrist, R., Sapsford, S., 2010, Experiments in Fluids, 48(1), pp. 133-142.

[9] Maligne, D. and Bruneaux, G., 2011, SAE Technical Paper, 2011-01-1215.

[10] Yang, B. and Ghandhi, J., 2007, SAE Technical Paper, 2007-01-0485.

[11] Ding, C.-P., Sjöberg, M., Vuilleumier, D., Reuss, D.L., He, X., Böhm, B., 2018, Experiments in Fluids, 59(3), 59:59.

[12] Le, Z., Zhihao, Z., Xiucheng, Z., Nitisha, A., Jeffrey, N., Seong-Young, L., 2018, SAE Technical Paper, 2018-01-0312.

[13] Henkel, S., Beyrau, F., Hardalupas, Y., Taylor, A M K P, 2016, Optics express, 24(3), pp. 2542 2561.

[14] Miyashita, K., Tsukamoto, T., Fukuda, Y., Kondo, K., Aizawa, T., 2016, SAE Technical Paper, 2016-01-2165.

[15] Bardi, M., Payri, R., Malbec, L.Marie, Bruneaux, G., M. Pickett, L., Manin, J., Bazyn, T., Genzale, C., 2012, Atomization and Sprays, 22(10), pp. 807-842.

[16] Bardi, M., Bruneaux, G., Nicolle, A., Colin, O., 2017, SAE Technical Paper, 2017-01-0721.

[17] Mesh and geometry, https://ecn.sandia.gov/gasoline-spray-combustion/computationalmethod/mesh-and-geometry/.

[18] Berlman, I., 1965, "Handbook of fluorescence spectra of aromatic molecules", Academic press.

[19] Rouessac, F., Rouessac, A., 2004, "Analyse chimique - 6ème édition", Dunod.

[20] Bardi, M., Di Lella, A., Bruneaux, G., 2019, Fuel, 239, pp. 521-533. 